\title{
Broadband: An Insight and Its Benefits
}

\author{
Joel Devardhi J \\ EThames Graduate School, The Towers, Towers Business Park, Wilmslow Road, Manchester, \\ M20/21, United Kingdom
}

\begin{tabular}{|c|c|}
\hline $\begin{array}{l}\text { Countries around the world have nominated broadband network as establishing } \\
\text { an information society for achieving their social, economic and scientific goals. } \\
\text { Broadband has been a beacon for investors and a stimulus for entrepreneurs } \\
\text { and mainstream businesses. This has intensified debates about the public } \\
\text { interest in information and communications infrastructure. Broadband enables } \\
\text { dramatically different patterns of use that offer the potential for significant } \\
\text { changes in lifestyle and business. It is viewed by some as a double-edged } \\
\text { sword: networking could promote economic development, yet electronic } \\
\text { commerce also has the potential to displace local businesses. The paper } \\
\text { focuses on defining broadband, identifying and assessing the benefits of } \\
\text { broadband technologies. Although broadband technologies are being widely } \\
\text { adopted by consumers, and heavily promoted by governments, it is observed } \\
\text { that their impacts to date are subtle, rather than spectacular. }\end{array}$ & Article Information \\
\hline \multirow{11}{*}{$\begin{array}{l}\text { Countries around the world have nominated broadband network as establishing } \\
\text { an information society for achieving their social, economic and scientific goals. } \\
\text { Broadband has been a beacon for investors and a stimulus for entrepreneurs } \\
\text { and mainstream businesses. This has intensified debates about the public } \\
\text { interest in information and communications infrastructure. Broadband enables } \\
\text { dramatically different patterns of use that offer the potential for significant } \\
\text { changes in lifestyle and business. It is viewed by some as a double-edged } \\
\text { sword: networking could promote economic development, yet electronic } \\
\text { commerce also has the potential to displace local businesses. The paper } \\
\text { focuses on defining broadband, identifying and assessing the benefits of } \\
\text { broadband technologies. Although broadband technologies are being widely } \\
\text { adopted by consumers, and heavily promoted by governments, it is observed } \\
\text { that their impacts to date are subtle, rather than spectacular. }\end{array}$} & Article History: \\
\hline & Received : 24-04-2012 \\
\hline & Revised : 20-06-2012 \\
\hline & Accepted : 26-06-2012 \\
\hline & Keywords: \\
\hline & Broadband \\
\hline & Technology \\
\hline & Consumers \\
\hline & ${ }^{*}$ Corresponding Author: \\
\hline & Joel Devardhi J \\
\hline & $\begin{array}{l}\text { E-mail: } \\
\text { floydliddle@yahoo.co.uk }\end{array}$ \\
\hline
\end{tabular}

\section{INTRODUCTION}

The recent recognition of the Internet and World Wide Web with both consumers and firms suggests that markets requiring telecommunications networks capable of interactive high-speed data transfers may emerge in the near future. Although broadband technologies are being widely adopted by consumers, and heavily promoted by governments, it is observed that their impacts to date are subtle, rather than spectacular. The paper focuses on identifying and assessing the benefits of broadband technologies. It begins with the definition of broadband briefly outlining the history of consumer broadband development. The issues driving broadband development, deployment and adoption are outlined from the perspectives of multiple stakeholders. The paper then outlines and assesses social and economic benefits of broadband infrastructure deployments, showing that evidence supporting the value of broadband initiatives is mixed. Broadband developments do support commercial interests, and there is evidence of increased efficiency in services delivered with broadband networks.

\section{Defining Broadband}

The term itself, originating in the characterization of a communications channel's capacity (in contrast to narrowband), has come to be used as, among other things, a marketer's label for advanced cable television service, the $21^{\text {st }}$ century incarnation of the early 1990s "information superhighway," and one element of the next stage in the development of the Internet. Broadband has been a beacon for investors and a stimulus for entrepreneurs and mainstream businesses. This has intensified debates about the public interest in information and communications infrastructure. Broadband Internet infrastructure has been a priority of governments around the world for many years. Why has broadband become such a desirable technology for governments and citizens? The Online Webster's Dictionary defines broadband 
Joel Devardhi

as "A class of communication channel capable of supporting a wide range of frequencies, typically from audio up to video frequencies. A broadband channel can carry multiple signals by dividing the total capacity into multiple, independent bandwidth channels, where each channel operates only on a specific range of frequencies. "Broadband Internet offers faster speeds than can be achieved with a dial-up telephone connection, allowing users an enhanced Internet experience. As a result, there have been many efforts to define 'broadband,' efforts that can be characterized by their technical or user-centric focus.

\section{Technical Definitions and Functioning of Broadband}

The demand and need for Broadband Internet arose when more and more people started using the internet. As internet became a reliable way to communicate and perform various functions, the need for speedy transmission of data also increased. Telephone lines could achieve speeds of maximum $56 \mathrm{Kbps}$ with the help of a high speed modem and while being used only for voice communication a telephone line could carry up to $29.6 \mathrm{Kbps}$ of analog data. The difference between telephone and broadband is telephone line has only one path or channel to send information. While broadband has multiple channels and these can be used at the same time.

Various types of data, frequencies with wider range can be accommodated by broadband internet. Broadband internet always gives its best in sending data at a faster rate if it can. Comparisons can be made between a wide tunnel and broadband. Greater breadth of Broadband allows more information to pass through, just like a wide tunnel can allow more traffic to pass through it. Hence speed of your broadband internet connection is directly related to its bandwidth. Broadband internet can compress and transmit data, thus making the experience of using internet a joyful one.

Fransman, (2006) argues that technical definitions of broadband reflect the perspective of those supplying and provisioning the networks, but that user-centric definitions are what really matters. Users will find value in broadband only if it allows them to do the things that they want to do. Demand for broadband networks is based on the networks offering sufficient capacity to meet users' needs. Technical definitions of broadband focus on the speed of the connection. Technical definitions also note that broadband connections
Sci. Technol. Arts Res. J., April-June 2012, 1(2):53-58

are 'always-on,' and that DSL (digital subscriber line) connections allow users to talk on the telephone while using their broadband connection. In the U.S., the Federal Communications Commission (FCC) defines a broadband connection as one that transmits data at rates of at least 200 kilobits per second (Kbps), in one direction (Federal Communications Commission, 2006). Broadband connections can be symmetrical (with the same upload and download speeds), or asymmetrical (typically the download speed is higher than the upload speed). The OECD's definition is similar to the FCC's, considering any connection with download speeds in excess of $256 \mathrm{Kbps}$ to be a broadband connection (Organization for Economic Co-operation and Development, 2007b).

\section{Features of Broadband Internet}

As Gault and Messinger, (2002) note, "While ICT infrastructure is important, its impact depends on what is displayed, processed, stored, and transferred by the network. Electronic content is what matters to the people downloading music, games, videos, and software" The World Summit on the Information Society (held in Geneva in 2003 and Tunis in 2005) recognized that "access to information and sharing and creation of knowledge contributes significantly to strengthening economic, social and cultural development" (World Summit on the Information Society, 2005, Item 10), and reaffirmed the Importance of information and communication technologies (ICTs) as a means of providing access to information and creating knowledge.

- It enables transfer of huge amount of data, and this is because of its high speed. The transmission speed is equal to 200,000 bps (i.e.) $200 \mathrm{Kbps}$ as compared to dial-up that has a speed of only $56 \mathrm{Kbps}$. This huge variance in speed makes Broadband more preferable over Dial-up and is used in the Banking Sector.

- Waiting time for connectivity and downloading is minimum and this is due to the greater speed that Broad Internet offers. Therefore games and video streaming that have large quantities of data being transferred can be preferred to be accessed over broadband Internet. E.g.: VOIP (Voice Over Internet Protocol).

- Real time chatting and video conferencing becomes easy and less tiresome and this can be attributed to its Speed. Hence activities like having the webcam on while chatting, video 


\section{Joel Devardhi}

conferencing in real time is possible and is widely used in corporates and households worldwide.

- Comfort of using Internet and telephone together is one of the best features of Broadband Internet. Therefore to establish a connection dial-up is not necessary and disruption in service due to blocking of telephone lines is removed as Broadband does not use Telephone lines for connectivity.

- Broadband Internet brings with it $24 \mathrm{hr}$ Connectivity, hence users can access the internet throughout the day without the need of logging to get connected each and every time. This is how the banking sector developed the concept of $24 \mathrm{hr}$ banking thus providing customers access to their accounts and details $24 / 7$.

- Due to wireless technology, Internet can now be accessed while travelling via Laptop, Palmtop and mobile phone. Banking services make use of these features buy providing the customer details of his account like if any money has been credited or debited instantly by using WAP. So, the customer knows what is going on his account by just accessing his e-mail or reading text message on his mobile phone sent by the bank.

- Broadband Internet brings with it not just Higher speed but one more added advantage of being affordable as billing is done based on a plan provided by the Internet Service Provider and not on the hours of access.

- Technologies of Broadband Internet include
I. ADSL.
II. SDSL.
III. Wireless Broadband Internet Connection.
IV. Satellite Broadband Internet Connection.

V. Cable Broadband Internet Connection.

VI. Fiber Optic Broadband Internet Connection.

\section{Impact of Broadband on the Business Sector}

By the early 2000 s, broadband was recognized as a key element of an information society, and governments around the world developed strategies to encourage the development of broadband infrastructures that would enable network access for all citizens. Broadband networks are that broadband delivers a high bandwidth Internet connection to a personal computer, which is usually located in a fixed location in an individual's home or office. Newer devices also allow for broadband service to connect televisions or game consoles directly to the Internet.
Sci. Technol. Arts Res. J., April-June 2012, 1(2):53-58

The emergence of wireless (Wi-Fi) networks allows people to use the Internet in a portable manner, by connecting laptop computers to the Internet in various locations within the home, or outside the home at public locations including airports, hotels, cafés and parks. But portability is not the same as mobility. Mobile broadband (e.g. high speed connections that can be used in a moving vehicle) allows users to do the things they want to anytime, anywhere availability that consumers currently have with cell phone service, and suggests that a more appropriate definition for broadband in today's environment would be a service that allows users to do what they want to do, where they want to do it, on the device(s) of their choice.

With the advent of internet millions of people are able to carry out Banking transactions through their PC's. Almost everything is done online. No more waiting in long queues for a simple transaction. Bank loans, shopping, cancellations of direct debits, statements, transfer of money, all the above tasks are performed online. It also has reduced the use of paper.

In Internet banking system data is maintained in a centralized database that is web enabled. Intranet is used to connect various branches to the main branch. SWIFT is example of Intranet.

Faster Service: The service time has been reduced to a great extent because of the bank functions or services are done online thus bringing down administrative costs.

Accessibility and Ease: You can access details such as personal information, transactions and also make necessary changes directly online instead of taking leave from work just for work at the bank. By having online banking services, it is easier to check if any unnecessary or wrong charges have been added to your account. Stock Trading, exchanging of bonds, almost everything is done online from your Laptop or PC.

Providing Up to Date Information: Policies, change in interest rates and procedures that need to be followed are made available online, this gives the customer a greater choice, as he can go through policies of different banks and choose what is best for them. Hence, creating what is called a 24/7 Banking.

Core Banking Solutions: The entire banking system has become more efficient as banking has become less time consuming and a pleasure as well. This combination of information and communication technology to meet the core 
needs of banking is called Core Banking Solutions. Branches of bank use special software and this interconnectedness are achieved by using communication lines like telephones, satellite and internet. Core operations like recording of transactions, passbook maintenance calculation of interest on loans and deposits, customer records, balance of payments and withdrawals are the functions carried out by this software.

Electronic Clearing Service: This service is useful for customers who would like to make and receive payments. They can avail this payment by filling up a form for ECS mode of credit and debit. The date of payment has to be set by the customer and must be told to the sponsor bank. Thereafter the customer can carry out his transactions electronically.

Mobile Banking: Banking can be done by using a mobile phone. Information is sent through SMS's to customers' mobile phones or via the internet used on the mobile phone.

\section{The Cost Structure of Broadband Networks}

Broadband, in the sense of high-capacity communications channels, is already present throughout much of the communications infrastructure. Fiber optic links with very large capacity are already commonplace within the networks of telecommunications carriers and are available for local access in many locations, albeit at high costs affordable by only larger businesses or organizations. The broadband challenge on most people's minds today is how to make higher-capacity connections available on a more pervasive, affordable basis.

\section{Cost Structure of Broadband Infrastructure}

There are generally three types of costs associated with communications systems: (i) a cost per unit of usage10 (such as a minute or a packet); (ii) a cost per user (such as the cost of the access connection); and (iii) a cost per potential user of service availability (such as the cost to extend, say, a fiber optic line down a street).

What technology will be used to provide broadband access, with hybrid fiber-coax (HFC, also called cable modem) and DSL (over telephone lines) the leading contenders? At this time, HFC, which consists of a fiber-optic network connected to homes and businesses using coaxial cable, is the only contender which can provide true broadband (up to $10 \mathrm{Mbps}$ ) at reasonable cost.
Once a network is built with a specific geographic scope, then the network can be used to provide service to everyone within this market region, and no one outside this region. In order to serve a single customer in a neighborhood (say, a city block), a network service provider must provide a facility (say, a fiber optic cable passing under the street) that is capable of serving all the households in that neighborhood. It is this property of network investment that leads to the unusual market equilibrium. The Internet is based on a common set of protocols that allow data to be transmitted over a variety of networks and viewed on a variety of platforms. That means that interconnection of broadband access networks is to some degree a foregone conclusion, and there may not be the same firm-specific network externalities. Broadband can be directly related to overall economic productivity which is weak, but persistent and firmly entrenched in international and national discussion about the value of broadband. It seems inevitable that the enthusiasm for broadband as a contributor to national productivity will continue, in step with broader claims about the value of ICT investments as a means of fostering an information society.

\section{The Benefits of Broadband}

The consumers are embracing broadband connections, and great efforts have been made at international and national levels to promote the development of broadband networks and services. Governments may develop, deploy and adopt broadband networks for use in delivering government services, without opening these networks for public use. Individuals may access government services using their own home broadband connections, or they may benefit from the delivery of broadband services to their communities. As demand for broadband grows, the cycle is repeated, in order to increase the capacity of broadband networks.

To understand the benefits of broadband technologies, it is useful to consider the stages involved in developing broadband technologies. The cycle begins with a promotion and planning stage, influenced by international discourse on the benefits of broadband, and potentially involving various levels of government, communities and industry (e.g. telecommunications equipment manufacturers and consultants). After a planning process, broadband networks are deployed, creating a supply of broadband to meet the needs of broadband consumers. However, as the OECD broadband penetration statistics show, simply 
Joel Devardhi

developing broadband infrastructure does not in itself result in broadband adoption. Adoption is a result of demand for broadband services. Demand can only be satisfied when broadband is supplied (the lack of supply is referred to as a broadband digital divide), but supply does not result in universal adoption. It is also noted that supply and demand can take place at different levels, and in different locations.

Annual growth of Internet hosts, for example, has been a phenomenal $25 \%$ for the last decade, and appears to have increased in the last several years. Although the Internet was designed and developed by academic researchers, principally in the physical sciences, the advent of the World Wide Web and browser technology in the early 1990s has fostered growth outside the academic community. In mid 1994, the number of commercial sites (the "com" domain) exceeded the number of educational sites (the "edu" domain) for the first time, indicating a strong commercial interest in reaching this new audience of consumers (rather than researchers). In addition, many see this form of communication as a critical input for primary and secondary education.

Gillett and colleagues (Gillett, et al., 2006) do provide initial evidence that the "assumed economic impacts of broadband are real and measurable" Societal benefits of broadband potentially extend to everyone in society, showing how the availability of broadband connectivity led to increases in the growth rates for jobs and the establishment of businesses. Broadband networks can be adopted by local agencies or entire communities, to support the provision of government services, and to encourage local innovation and knowledge access Communal benefits are realized within a specific community (e.g. province, city, rural area, community group). Broadband can help to overcome challenges of distance and high costs of service delivery for those living in rural or remote areas, Popular online activities made possible by access to broadband networks include watching videos on YouTube or through video on demand services, buying music and television shows from iTunes, or accessing entertainment content for free using file sharing services like Bit Torrent. People keep track of their friends and communicate with them within social networking sites like Facebook or MySpace. Individual benefits accrue primarily to individuals, within their households. The promotion of broadband technologies is beneficial to a wide range of companies, from multinational equipment manufacturers e.g. Nortel, Cisco, Corning, Motorola, Siemens, Alcatel) to
Sci. Technol. Arts Res. J., April-June 2012, 1(2):53-58

telephone and cable companies worldwide (e.g. Bell, Rogers, Cogeco, Shaw, Telus in Canada), semiconductor manufacturers, consulting firms, software manufacturers, content and service providers (e.g. Google, Yahoo),hardware (personal computers and commercial servers) providers and others. Commercial revenues are generated at every stage of the broadband cycle, and increase as broadband penetration and usage increases. Commercial benefits accrue to individuals and businesses involved in the commerce of broadband (e.g. Internet service providers, telecommunications equipment manufacturers, computer hardware and software providers, etc.).

Therefore how can one best extend high-speed connectivity to users in homes, small businesses and smaller offices of larger organizations, local governments, and so forth? Widespread usemarked by new patterns of information flow-not only would benefit the individuals connected, but also could lead to qualitative changes in how people interact with family, community, and the workplace, with potentially profound social and economic implications. Broadband is viewed by some as a double-edged sword: networking could promote economic development, yet electronic commerce also has the potential to displace local businesses.

\section{CONCLUSIONS}

Broadband enables dramatically different patterns of use that offer the potential for significant changes in lifestyle and business. Broadband is a means to multiple, diverse ends encompassing family, work, and society generally. The term "broadband" is very much a moving target. While the broadband of today consists of, for the most part, cable modem and DSL connections, the broadband of the future may very well be based on fiber optic cable or wireless technologies. The implications of this for those actively promoting cable and DSL may be highly significant. Will promoting the broadband of today serve as a necessary stepping-stone for the adoption of future broadband technologies? Will those countries that have low take-up of broadband today lose out on the advantages of a widespread rollout and fall too far behind to catch up? Broadband promotion is likely to be most effective when various initiatives and projects are integrated, encompassing all stakeholder groups.

The benefits of broadband adoption at the societal, communal, individual and commercial levels were identified and assessed, concluding that the case for broadband is mixed. Although 


\section{Joel Devardhi}

broadband provides some benefits at all levels, evidence for the much-touted transformational effects of broadband is lacking. There are many examples showing how broadband can be adopted to improve efficiencies in service delivery, and it is clear that individuals are enthusiastic consumers of broadband for communication and entertainment purposes.

Broadband networks stimulate both offer and demand for richer and more diversified content using fine-tuned user profiles in better-focused markets, thus increasing profitability. At the same time, content and service providers can address a much wider customer base thanks to direct access to worldwide markets. All stakeholders will benefit from increased revenues.

\section{REFERENCES}

Alberta Super Net. (2005). Benefits of Alberta Super Net. Retrieved 11 May, 2007, from http://www. albertasupernet.ca/Benefits/default.htm.
Sci. Technol. Arts Res. J., April-June 2012, 1(2):53-58

Computer Science and Telecommunications Board. (2002). Broadband: Bringing Home the Bits. Washington, DC: National Academy Press.

Fiser, A., Clement, A., Walmark, B. (2005). The K-Net Development Process: A Broadband Model for First Nations Community Networking. Paper presented at the Telecommunication Policy Research Conference, Arlington, VA.

Fransman, M. (2006). Global Broadband Battles: Why the U.S. And Europe Lag While Asia Leads. Stanford: Stanford Business Books.

Gault, F., Messinger, H. (2002). Measuring the Networked Economy (No:F0006XIE). Ottawa: Statistics, Canada.

Gillett, S.E., Lehr, W.H., Osorio, C. (2004). Local Government Broadband Initiatives. Telecommunications Policy 28(7-8): 537-558.

Gillett, S.E., Lehr, W.H., Osorio, C. A., Sirbu, M.A. (2006). Measuring Broadband's Economic Impact: Final Report. Washington, DC: U.S. Department of Commerce, Economic Development Administration.

World Summit on the Information Society. (2005). Tunis Commitment. Retrieved 10 May, 2007, from http://www.itu.int /wsis/docs2/tunis/off/7.html. 